Revista Destaques Acadêmicos, Lajeado, v. 10, n. 4, 2018. ISSN 2176-3070

DOI: http://dx.doi.org/10.22410/issn.2176-3070.v10i4a2018.1979

http://www.univates.br/revistas

\title{
NÚMEROS x ALFABETO: O PROFESSOR E SUA CONCEPÇÃO DE ÁLGEBRA
}

\author{
Jadson de Souza Conceição ${ }^{1}$, Marcus Vinícius Costa dos Santos², \\ Tamiles da Silva Oliveira ${ }^{3}$
}

\begin{abstract}
Resumo: O presente artigo é fruto de leituras, discussões e experiências geradas durante as aulas da disciplina Álgebra Superior na Perspectiva da Educação Matemática, oferecida pelo Programa de Pós-Graduação em Educação Matemática da Universidade Estadual de Santa Cruz (PPGEM/UESC). O texto em questão objetiva analisar as concepções de Álgebra explicitadas por professores, com base nas ideias propostas por Usiskin, ao elaborarem situações-problema envolvendo conceitos algébricos da Educação Básica. Para a produção e coleta dos dados, participaram do estudo 13 professores que elaboraram 26 situações-problema envolvendo conceitos algébricos da Educação Básica. Os dados foram analisados e classificados segundo as concepções de álgebra propostas por Usiskin. As situações-problema apresentadas pelos professores evidenciaram a necessidade de pensar o ensino da álgebra para além do ato da resolução de problemas, isto é, um ensino com ênfase na aquisição e apreensão cognoscível que se torne significativo para o educando, em detrimento de metodologias que se pautem unicamente na manipulação de letras e números.
\end{abstract}

Palavras-chave: Álgebra. Ensino de Álgebra. Concepções de Álgebra.

\section{INTRODUÇÃO}

Dados históricos apontam que a construção da notação algébrica constituiu-se em três estágios: retórico, no qual as estratégias eram apresentadas em forma de texto, sem nenhuma simbolização; sincopado, no qual foram empregadas algumas abreviações, mais especificamente para representar

1 Licenciado em Matemática pela UFRB. Mestre em Educação Matemática pela Universidade Estadual de Santa Cruz - UESC. Professor Substituto do Instituto Federal da Bahia - IFBA.

2 Licenciado em Matemática pela UFBA. Mestre em Educação Matemática pela Universidade Estadual de Santa Cruz - UESC. Professor Substituto da Universidade Federal da Bahia UFBA.

3 Licenciada em Matemática e Mestre em Educação Matemática pela Universidade Estadual de Santa Cruz - UESC. Professora do Centro Universitário Leonardo Da Vinci - UNIASSELVI. 
incógnitas; e simbólico, no qual as representações foram resumidas por símbolos e as letras passaram a assumir papéis duplos, ou seja, de incógnitas ou variáveis (BOYER, 1996). Observemos alguns exemplos desses estágios:

Retórico: Consideremos um número que somado com quatro seja igual ao seu dobro. dobro.

Sincopado: Seja $x$ o número que somado com quatro seja igual ao seu

Simbólico: $x+4=2 x$.

A fase antiga da álgebra ocorreu no período de 1700 a.C. a 1700 d.C. e caracterizou-se pela construção gradativa da relação da simbologia com a solução de equações. Todavia, na Educação Básica, esta simbolização algébrica, que levou mais de 3000 anos para ser validada, ocorre de maneira muito precoce, não levando em consideração toda a construção histórica da álgebra. Segundo Schoen (2005, p. 138) "lançar os educandos precipitadamente ao simbolismo algébrico é ignorar a necessidade de uma fundamentação verbal e de uma simbolização gradual sugeridas pela construção histórica da álgebra". Assim, faz-se necessário, durante os processos de ensino e aprendizagem da álgebra, elencar reflexões acerca das metodologias que perpassam as suas abordagens e concepções.

A esse respeito, Fiorentini, Miguel e Miorim (1993) apontam que a álgebra, com sua característica pragmática e utilitária, enquanto meio para resolver problemas, integra o currículo da Educação Básica sem muita clareza e, muitas vezes, desprovida de significação, fazendo com que conceitos algébricos não sejam construídos de maneira satisfatória durante os processos de ensino e aprendizagem. Essas incongruências no ensino de álgebra têm feito com que os professores acentuem seus esforços sobre o ensino desse campo da matemática, o que também não tem garantido eficiência no processo de aprendizagem (PONTE, 2006). Diante desse contexto, instaura-se uma crença (por parte dos professores) em que aumentando-se o tempo de ensino dedicado à Álgebra, aliado à prática de exercícios, assegurar-se-ia uma aprendizagem com real significância, porém, tais esforços mostram-se ineficazes à medida em que as dificuldades percebidas no processo perpetuam-se continuamente.

\section{CONCEPÇÕES DE ÁLGEBRA}

Segundo Ponte (2005), durante muito tempo a Álgebra se fundamentou em equações e na sua manipulação. Contudo, atualmente, o grande desafio e objetivo dessa área é a construção do pensamento algébrico. Diante disso, a Base Nacional Comum Curricular - BNCC (BRASIL, 2017) e o Sistema Nacional de Educação (SNE), sugerem que conceitos algébricos sejam introduzidos ainda nos anos inicias, por meio do desenvolvimento de habilidades que permitam identificar atributos, regras de formação de sequências, reconhecimento de 
mudanças e relações como os primeiros indícios para a formação do pensamento algébrico e da ideia de função para os anos iniciais do Ensino Fundamental.

Porto (2018) destaca que "esse pensamento algébrico proposto precede a abordagem e a apropriação dos conceitos propostos pela Álgebra Elementar, pois não contempla a formação e manipulação de símbolos algébricos formais". Isto porque, a construção desses conceitos deverá ser realizada nos anos finais dos Ensinos Fundamental e Médio, como preconizado nas diretrizes curriculares nacionais.

Nos Parâmetros Curriculares Nacionais - PCN (BRASIL, 1998) e na BNCC (2017), destaca-se que a construção do pensamento algébrico deve ser desenvolvida a partir de situações que relacionem as diferentes concepções de álgebra, além disso, devem ser asseguradas por meio de atividades de caráter investigativo e exploratório, pois estas contribuem para o desenvolvimento de atividades relacionadas ao pensamento algébrico (ABRANTES, SERRAZINA e OLIVEIRA, 1999; LEITÃO e CANGUEIRO, 2007).Isto porque, a álgebra possibilita ao aluno desenvolver e exercitar sua capacidade de abstração e generalização em vários campos da Matemática e em outras ciências (BRASIL, 1998).

Nesse sentido, faz-se necessário compreender as diferentes concepções de Álgebra para seu ensino. Usiskin (2005), levando em consideração os diferentes usos das variáveis, propõe quatro concepções de Álgebra, a saber: (i) a álgebra como aritmética generalizada, (ii) a álgebra como um estudo de procedimentos para resolver certos tipos de problemas, (iii) a álgebra como estudo de relações entre grandezas, e, por fim, (iv) a álgebra como estudo das estruturas.

No que se refere a primeira concepção, a álgebra como aritmética generalizada, é natural pensar as variáveis enquanto generalizadoras de modelos, haja vista que é comum em algumas situações buscarmos generalizar, como exemplo: afirmarmos, pela propriedade comutativa da operação de adição, que expressões como $3+5.7=5.7+3$, podem ser generalizadas por, como exemplo, $a+b=b+a$. Diante disso, nesta concepção, os alunos são orientados a traduzir e generalizar modelos, como o exemplo mencionado. Assim, o traduzir e o generalizar são técnicas importantes, não apenas para a álgebra, mas também para a Aritmética, haja vista que o estudo adequado da aritmética depende direta ou indiretamente dos conceitos algébricos (USISKIN; BELL, 1984).

Na segunda concepção, a álgebra como um estudo de procedimentos para resolver certos tipos de problemas, as variáveis não são mais interpretadas como generalizadoras, mas como incógnitas ou constantes, como pode ser observado no exemplo 1 a seguir. 
Exemplo 1: Adicionando 3 ao quíntuplo de um certo número, a soma é 40. Determinar esse número.

Fonte: Usiskin, 2005.

Note que, ao traduzir esse problema para a linguagem algébrica, obtemos a seguinte expressão: $5 x+3=40$. Ainda é possível observar que, diferente da primeira concepção, em que os alunos são induzidos a traduzir e generalizar, nesta segunda os alunos precisam simplificar e resolver. Assim, ao resolver problemas semelhantes ao do exemplo 1, muitos alunos apresentam dificuldades na passagem da Aritmética para a Álgebra (USISKIN, 2005). Isto porque, enquanto a resolução aritmética consiste em subtrair 3 de 40 e dividir este resultado por 5, a forma algébrica $5 x+3$, envolve a multiplicação por 5 e a adição de 3, operações inversas. Ou seja, para montar a equação, é preciso raciocinar de maneira contrária àquela que empregaríamos para resolver problemas aritméticos, o que, na maioria das vezes, não é algo simples para os alunos.

No que diz respeito à terceira concepção, a álgebra como um estudo de relações entre grandezas, as variáveis são interpretadas no seu significado mais puro, isto é, as variáveis são mutáveis. Dentro dessa concepção, uma variável pode representar dois papéis: (i) os valores do domínio de uma função (um argumento) e (ii) um número do qual dependem outros números (um parâmetro) (USISKIN, 2005). Observemos os exemplos 2 e 3, nos quais são apresentados esses dois papéis que uma variável pode assumir.

Exemplo 2: Considere $A=a . b$ a fórmula Exemplo 3: O que acontece com o para determinar a medida de área de valor de $1 / x$ quando $x$ se torna cada um retângulo de lados $a$ e $b$. vez menor?

Fonte: Usiskin, 2005.

Note que no exemplo 2 estamos lidando com a fórmula do cálculo de área de um retângulo, de lados $a$ e $b$, expressando uma relação entre as grandezas: área, base e altura. Desta forma, não nos parece que estamos lidando com incógnitas, pois, nesses casos, não há o que resolver. Considerando que a concepção da álgebra como estudo das relações pode começar com a manipulação de fórmulas, o que a difere da concepção anterior, podemos perceber essa diferença de maneira mais explícita no exemplo 3, em que há um modelo a ser generalizado, mas não se trata de um modelo que se pareça com a aritmética. Segundo Usiskin (2005), é devido a essa natureza algébrica que alguns educadores em Matemática concordam que a Álgebra deve ser introduzida por meio da utilização da variável (FIORENTINI, MIGUEL, MIORIM, 1993; PONTE, 2006). 
A quarta e última concepção proposta por Usiskin (2005), a álgebra como um estudo das estruturas, tem como foco o ensino da Álgebra enquanto estudo das estruturas pelas propriedades e operações que atribuímos aos números reais e polinômios, fazendo com que os estudantes a reconheçam dessa forma. O exemplo 4, explícita a ocorrência desta concepção.

Exemplo 4: Fatorar o polinômio $3 x^{2}+4 x=132$.

Fonte: Usiskin, 2005.

Salientamos que, nesta concepção, a noção de variável não coincide com nenhuma das discutidas anteriormente, visto que o exemplo apresentado não faz referência a uma situação que diz respeito a uma função ou ainda, uma relação. Além disso, a variável não é um argumento, bem como não há uma equação a ser resolvida, logo, a variável não atua como incógnita. Do mesmo modo, não há um modelo aritmético a ser generalizado. Portanto, na concepção de álgebra como um estudo das estruturas, a variável é pouco mais que um símbolo arbitrário, estando, meramente passível de manipulações para dar origem às expressões (USISKIN, 2005).

Diante do exposto, é de se notar a necessidade de passear pelas diferentes concepções de álgebra com intuito de que, nos processos de ensino e aprendizagem, sejam construídos conceitos algébricos que permitam aos alunos explorá-los em diferentes contextos e situações com níveis de complexidade distintos. Pois, segundo Oliveira e Laudares (2015, p.2) "as abordagens, tradicionalmente difundidas em torno da Álgebra têm colocado em foco principalmente a memorização e mecanização de fórmulas, como metodologia para assimilação dos conceitos algébricos", sendo esse tipo de abordagem prejudicial para a construção do pensamento algébrico, bem como para a compressão de operações elementares.

Nessa perspectiva, faz-se necessário que o professor esteja envolvido com programas de formação continuada, cujo grupo em formação reflita de maneira coletiva sobre as práticas de sala de aula. Portanto, podemos concordar que a formação do professor envolve muito mais que provê-lo de conhecimentos específicos de sua matéria de ensino (CONCEIÇÃO, 2018), pois, além de criar condições para a compreensão de perspectivas educacionais relacionadas às diferentes concepções de Álgebra e auxiliar a integração destas na sua prática pedagógica, deve possibilitar ao professor a passagem de um sistema de ensino sem muita clareza e desprovido de significado (FIORENTINI; MIGUEL; MIORIM, 1993) para uma abordagem que integre as diferentes concepções, situações e contextos. 


\section{MATERIAIS E MÉTODOS}

O objetivo deste estudo centrou-se em analisar as concepções de álgebra explicitadas por professores, com base nas ideias propostas por Usiskin (2005), ao elaborarem situações-problema envolvendo conceitos algébricos da Educação Básica. Para alcançar tal objetivo, inicialmente, apresentamos a proposta de atividade aos 13 professores que se encontravam em formação continuada, nível mestrado acadêmico, no Programa de Pós-Graduação em Educação Matemática da Universidade Estadual de Santa Cruz - PPGEM/ UESC e cursavam a disciplina Álgebra Superior na Perspectiva da Educação Matemática.

É válido salientar que a atividade ocorreu em dois momentos distintos e complementares: (i) elaboração das situações-problemas e (ii) socialização das análises. Nesta última, de posse das 26 situações-problema elaboradas pelos professores, interpretamo-nas e as classificamos segundo as concepções de álgebra proposta por Usiskin (2005). Em seguida, apresentamos os resultados da análise aos professores num momento de socialização dentro da disciplina em curso. Neste momento de socialização, pretendia-se induzir os professores a refletir sobre suas situações, bem como sua sala de aula com vistas a ampliar seus horizontes para as diferentes concepções de Álgebra.

Após apresentar a atividade e explicar sua dinâmica, distribuímos entre eles fichas individuais (ver Figura 1), nas quais eles redigiriam suas situaçõesproblema referentes aos conceitos algébricos propostos para a Educação Básica.

Figura 1: Ficha para elaboração das situações-problemas

\begin{tabular}{l} 
Nome: \\
Atua como professor do Ensino: \\
( ) Fundamental (Anos Finais) ( ) Médio ( ) Superior \\
Elabore duas situações-problemas envolvendo conceitos \\
algébricos da Educação Básica. \\
\hline Problema 1: \\
\hline \\
\hline Problema 2: \\
\hline \\
\hline
\end{tabular}

Fonte: Elaborado pelos autores. 
A escolha dessa atividade foi pensada de modo a explorar as concepções de álgebra que estes professores apresentavam, assim como estas se manifestaram na elaboração das situações-problema. Por meio desse movimento de criar situações-problema, é possível que o professor reflita sobre sua sala de aula e seu fazer pedagógico, na tentativa de romper com a visão utilitarista da Matemática.

\section{RESULTADOS E REFLEXÕES}

Durante o processo de análise das situações elaboradas pelos professores, identificamos que estas permeiam as quatro concepções de Âlgebra propostas por Usiskin (2005): aritmética generalizada; meio de resolver problema; estudo de relações e estrutura. Todavia, 18 das situações elaboradas estavam relacionadas à álgebra enquanto meio para resolver problemas, (USISKIN, 2005), como pode ser observado no Gráfico 1, a distribuição de cada categoria, evidenciada pelos professores participantes do estudo.

Gráfico 1 - Quantitativo das concepções de Álgebra explicitadas pelos Professores

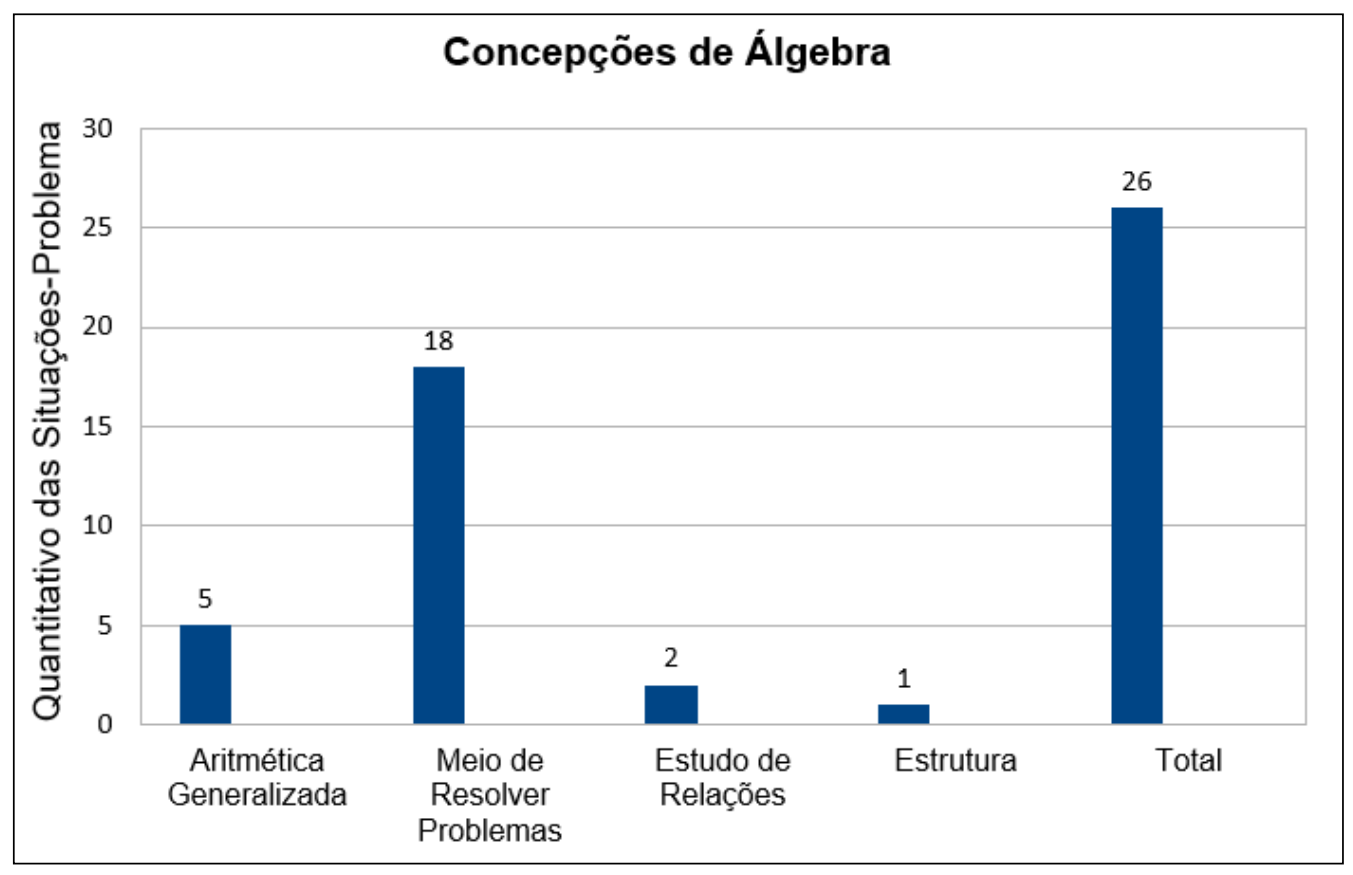

Fonte: Dados produzidos na pesquisa.

De acordo com o Gráfico 1, é possível perceber que o maior quantitativo das categorias de análise está concentrado na concepção 2, como fora explicitado. Das 26 situações analisadas, 18 envolvem essa concepção. Portanto, isso nos 
leva a inferir que as concepções explicitadas por esses professores tendem para um único significado atribuído a álgebra. E os menores quantitativos estão nas percepções da álgebra como estudo de relações entre grandezas e como estudo das estruturas, respectivamente, com duas e com uma situação.

Esses resultados podem ser preocupantes, pois os envolvidos na pesquisa são professores que atuam na Educação Básica. Ao apresentarmos e discutirmos com estes professores essa discrepância significativa na utilização das diferentes concepções da Álgebra, eles mostraram-se surpresos e puseramse em reflexão sobre os processos de ensino e aprendizagem, e sobre o quão importante é mobilizar as diferentes concepções da álgebra. Isto porque, os alunos podem compreender os diferentes significados que as variáveis podem assumir, quer seja como um número, como um sinal no papel ou como um símbolo que substituiu objetos, evitando assim erros conceituais com relação ao uso das variáveis. Para Usiskin (2005), a ideia de variável acarreta diversas definições, e enquadrar seu uso em uma única concepção pode confundir os objetos da Álgebra, pois as suas concepções estão ligadas às maneiras como se utilizam as variáveis

Outro dado importante identificado na análise e discutido de maneira coletiva com os professores, foi a existência de situações-problema sem solução. Isto é, alguns professores elaboraram situações inconsistentes que não permitiam nenhum tipo de resolução, e, quando solicitados a explicarem a situação elaborada os comentários eram vagos e acabavam confirmando a inexistência de uma solução.

Além disso, observamos a não existência de situações-problemas de caráter investigativo ou exploratório, estas que são importantes para o desenvolvimento do pensamento algébrico (ABRANTES, SERRAZINA e OLIVEIRA, 1999; LEITÃO e CANGUEIRO, 2007). A ausência de situações de viés investigativo ou exploratório, pode fazer com que os alunos não desenvolvam o pensamento algébrico de modo satisfatório, levando-os a memorizar e reproduzir fórmulas (Oliveira e Laudares, 2015). Todavia, das situações analisadas que permitiram soluções, destacamos quatro, uma para cada concepção, para compor o corpo desse relato, apresentamo-nas a seguir.

A Situação-problema 1, aborda um exemplo da situação que envolve a concepção de Álgebra como aritmética generalizada. Nela, o Professor A propõe um problema no qual, para sua resolução, é necessário seguir alguns passos, traduzir, para então apresentar uma solução e/ou generalização do problema.

Situação-problema 1 (Professor A): Sabe-se que o maior número possível divisível por 11 e menor que 300 é dado por 300 - $r$, em que $r$ representa o resto da divisão de 300 por 11 . Assim, qual o maior número, menor que 300 , que é divisível por 11 ?

Analisando a situação, é possível perceber que esta tem por objetivo induzir o aluno a pensar no número que é o resto da divisão de 300 por 11. 
entretanto, é possível pensarmos numa maneira de generalizar uma situação como esta. Assim, temos que, dados $x, y$ e $w$ números naturais, com $w<x<y$ e $y$ divisível por $w$, existe um número $x$ menor que $y$, também divisível por $w$ que pode ser escrito como $x=y-r$, onde $r$ é o resto da divisão de $y$ por $w$. Observe que a situação se exprime naquilo que é apresentado na Concepção 1: traduzir e generalizar. Entretanto, ao analisarmos a situação como um todo, esta determina os procedimentos que devem ser seguidos para obter a sua solução, impedindo a construção da autonomia e do ato de reflexão do estudante frente ao problema apresentado. Para Onuchic e Allevato (2014), problemas que apresentem tais características não devem ser considerados como problemas, pois o enunciado denota indicativos da resolução a ser realizada.

Apoiados nas ideais de Ponte (2006) inferimos que isso pode ser um reflexo da concepção de álgebra que esse professor traz consigo, a qual pode ter sido construída na academia, na relação com seus pares ou com o livro didático, ou ainda no período da sua Educação Básica. Acreditamos ainda que esse reflexo da concepção de Álgebra também tenha influenciado o Professor B na construção de suas situações, como pode ser observado na situação-problema 2 a seguir.

Situação-problema 2 (Professor B): Considere $2 x+3 x=15$. Calcule o valor de $x$.

A situação-problema proposta pelo Professor B é, um exemplo claro de uma situação que descreve a álgebra como meio de resolver problemas. Esse é um típico problema do paradigma do exercício (SKOVSMOSE, 2000), em que o aluno não é levado a refletir sobre os procedimentos que estão sendo realizados, à medida que apenas aplicam regras e métodos para resolução do problema (PONTE, 2006; Oliveira e Laudares, 2015). É possível observar ainda, que esta situação é uma equação, em que se espera que o aluno, por meio da manipulação dos símbolos e dos números determine o valor da incógnita $x x$, convergindo com as instruções-chave que descreve esta concepção: simplificar e resolver.

Apesar de ser apenas um problema e não termos dados suficientes para concluir que a concepção de Álgebra do Professor B seja a de meios para resolver problemas, é necessário que este conheça as demais concepções e proponha problemas que as envolvam, visto que a segunda situação-problema elaborada pelo professor também atendeu às características dessa concepção.

No que se refere à concepção 3 - Estudo de relações, o Professor $C$, propõe na situação-problema 3 um contexto que envolve relações entre grandezas.

Situação-problema 3 (Professor C): Pierre abasteceu seu carro com 5 litros de gasolina e pagou 15 reais: a) Quanto custou cada litro de gasolina? b) Determine uma expressão algébrica para indicar a quantia a ser paga, nesse mesmo posto, se um veículo for abastecido com $n$ litros. 
Na situação elaborada pelo Professor C é notória a relação entre grandezas, neste caso, litros de gasolina e reais, traduzindo-se em uma relação funcional. Nesse contexto, as variáveis variam e representam os valores do domínio de uma função, ela expressa, sobretudo, as relações e funções que, dentro dos conceitos e procedimentos, faz com que as grandezas variem e isto pode ser observado quando o Professor C, descreve no item a) que em 5 litros de gasolina ele pagou $\mathrm{R} \$ 15,00$ e questiona quanto custou cada litro, ou seja, é exigido do aluno uma interpretação sobre a relação funcional entre as grandezas litros de gasolina $\mathrm{x}$ reais.

Do mesmo modo, no item $b$ ) temos o valor a ser pago, em função dos litros de gasolina. Ou seja, uma relação de grandezas: $f(x)$, para $x=n$, sendo $x$ os litros de gasolina. A variável aqui representa os valores do domínio da função. É possível observar que há um modelo a ser generalizado, mas não se trata de um modelo que se assemelhe à Aritmética. Essa generalização não aritmética também pode ser observada na situação-problema 4, elaborada pelo Professor D.

Situação-problema 4 (Professor D): Uma pessoa encontra-se no quilômetro $A$ de uma estrada e pretende ir para o quilômetro $B$ desta mesma estrada. Sendo $A=5(x-3)-2 x(2 x-3)$ e $B=19-(2 x+1)^{2}$ com $x$ pertencente a $Z$. Qual a distância do quilômetro $A$ para o quilômetro $B$ ?

Ao analisarmos essa situação, identificamos que esta apresenta características da concepção 4, isto é, o estudo das estruturas, ao referir-se ao uso das letras para representar símbolos abstratos (quilômetros). Nesta situação, o Professor D, espera que o aluno utilize de meios e procedimentos e, por meio do cálculo algébrico, obtenha uma expressão que determine a distância entre os quilômetros A e B. Note que a situação proposta requer do estudante a manipulação das variáveis, usando propriedades da Álgebra, igualmente abstratas, mas não se pretende aqui, que ele pense em números, nem interessa, nessa situação, substituir valores, porque nesse caso seria uma generalização aritmética o que negaria a essência da situação, que neste caso pertence a concepção 4 e não a concepção 1 . Note que, quando o estudante fizer a subtração $B$ - $A$, obter-se-á uma outra expressão algébrica e não numérica, desse modo a resolução da situação-problema requer uma implicação da expressão.

Após apresentar e discutir as situações problemas elaboradas pelos professores, passamos a palavra para eles. Com a palavra, os professores relataram que se vislumbrarem a álgebra somente como manipulação de regras e símbolos, seus alunos encontrarão dificuldades nos cálculos algébricos e passarão a enxergar a álgebra de maneira negativa, o que pode contribuir para o desenvolvimento de dificuldades em sua aprendizagem. 


\section{CONSIDERAÇÕES FINAIS}

Este artigo objetivou analisar as concepções de álgebra explicitadas por professores, com base nas ideias propostas por Usiskin (2005), ao elaborarem situações-problema envolvendo conceitos algébricos da Educação Básica.

De acordo com a análise, pode-se perceber que as concepções dos professores direcionam para a segunda concepção: meio de resolver problema. Entendemos e reconhecemos que este estudo foi realizado com uma quantidade pequena de professores. Desse modo, temos a clareza de que não podemos generalizar os resultados para além do universo que compreende nosso estudo. Contudo, mostramo-nos otimistas em considerar que os resultados aqui apresentados podem contribuir para uma discussão a respeito das diferentes concepções de álgebra passíveis de serem abordadas na educação básica ou ainda, nos programas de formação continuada.

Concluindo, ratificamos a importância de o professor, ao trabalhar com álgebra na sala de aula, perpassar pelas diferentes concepções que a compõem, pois dessa forma é possível que os alunos ampliem seu campo de visão a respeito dos conceitos algébricos, permitindo-o explorá-los em diferentes contextos e situações. Assim, ratificamos a necessidade de, na formação do professor de Matemática inicial e/ou continuada, haver um estreitamento entre as relações de aprendizagem e as diversas formas de ensinar, bem como, especial atenção às questões referentes a álgebra.

\section{REFERÊNCIAS}

ABRANTES, P.; SERRAZINA, L.; OLIVEIRA, I.A matemática na Educação Básica. Lisboa: Ministério da Educação, 1999.

BOYER, C. B. História da Matemática. São Paulo: Edgard Bencher Ltda, 2003.

BRASIL. Base Nacional Curricular Comum. Secretaria de Educação Fundamental. Brasília: MEC/SEF, 2017.

BRASIL. Parâmetros Curriculares Nacionais: matemática. Secretaria da Educação Fundamental. Brasília: MEC/SEF, 1998.BRASIL.

CONCEIÇÃO, J. S. A construção do conceito de área nos anos iniciais do ensino fundamental: uma formação continuada. 203 f. Dissertação (Mestrado em Educação Matemática). Programa de Pós-Graduação em Educação Matemática. Universidade Estadual de Santa Cruz. Ilhéus, BA, 2018.

FIORENTINI, D.; MIORIM, M. A.; MIGUEL, A. Contribuição para um repensar... A educação algébrica elementar. Pro-Posições, São Paulo, n. 4, p. 78-91, 1993.

LEITÃO, A; CANGUEIRO, L. Princípios e Normas do NCTM - um percurso pela Álgebra. Grupo de trabalho das Publicações, da APM, 2007. Disponível em: www. 
apm.pt/files/ConfCangueiroLeitao487e4d92df2el.pdf. Acesso em 10 de janeiro de 2019.

OLIVEIRA, S. C.; LAUDARES, J. B. Pensamento Algébrico: Uma relação entre Álgebra, Aritmética e Geometria. In: VII Encontro Mineiro de Educação Matemática. 2015, São João Del Rei - MG. Anais... São João Del Rei - MG: UFSJ, 2015. v. 1. p. 1-12.

ONUCHIC, L. R; ALLEVATO, N. S. G; Ensino-aprendizagem-avaliação de matemática: por que através da resolução de problemas? In: ONUCHIC, L. R. (Orgs.). Resolução de problemas: teoria e prática. Jundiai: Paco Editorial, 2014. p. 35-49.

PONTE, J. P. Álgebra no currículo escolar. Educação e Matemática - Revista da Associação dos Professores de Matemática. Lisboa n. 85, nov./dez, 2005.

PONTE, J. P. Números e álgebra no currículo escolar. In: VALE, I; PIMENTEL, T; BARBOSA, A; FONSECA, L; SANTOS, L; CANAVARRO, L. (Orgs.). Números e álgebra na aprendizagem da Matemática e na formação de professores. Lisboa: SEMSPCE, 2006. p. 5-27.

PORTO, R. S. O. Early álgebra: prelúdio da álgebra por estudantes do $3^{\circ}$ e $5^{\circ}$ anos do ensino fundamental. 177f. Dissertação (Mestrado em Educação Matemática). Programa de Pós-Graduação em Educação Matemática. Universidade Estadual de Santa Cruz. Ilhéus, BA, 2018.

SCHOEN, H. L. Ensinar a álgebra elementar focalizando problemas. In: COXFORD, A. F; SCHULTE, A. P. (Orgs.). As ideias da Álgebra. Reston, VA: NCTM, 2005. p. 135144.

SKOVSMOSE, O. Cenários de investigação. Bolema- Boletim de Educação Matemática, Rio Claro, n. 14, p. 66-91, 2000.

USISKIN, S. Concepções sobre a Álgebra da escola média e utilizações de variáveis. In: COXFORD, A. F; SCHULTE, A. P. (Orgs.). As ideias da Álgebra. Reston, VA: NCTM, 2005. p. 8-19.

USISKIN, Z. BELL, M. Applying Arithmetic. Preliminary ed. Chicago: Department of Education, University of Chicago, 1984. 